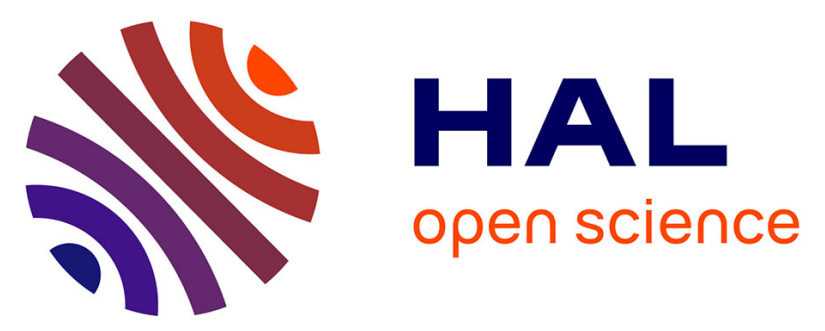

\title{
Tungsten oxide thin film exposed to low energy He plasma: Evidence for a thermal enhancement of the erosion yield
}

H. Hijazi, Y. Addab, A. Maan, J. Duran, D. Donovan, C. Pardanaud, Mona Ibrahim, M. Cabié, P. Roubin, Céline Martin

\section{To cite this version:}

H. Hijazi, Y. Addab, A. Maan, J. Duran, D. Donovan, et al.. Tungsten oxide thin film exposed to low energy He plasma: Evidence for a thermal enhancement of the erosion yield. Journal of Nuclear Materials, 2017, 484, pp.91-97. 10.1016/j.jnucmat.2016.11.030 . hal-01795748

\section{HAL Id: hal-01795748 \\ https://hal.science/hal-01795748}

Submitted on 18 May 2018

HAL is a multi-disciplinary open access archive for the deposit and dissemination of scientific research documents, whether they are published or not. The documents may come from teaching and research institutions in France or abroad, or from public or private research centers.
L'archive ouverte pluridisciplinaire HAL, est destinée au dépôt et à la diffusion de documents scientifiques de niveau recherche, publiés ou non, émanant des établissements d'enseignement et de recherche français ou étrangers, des laboratoires publics ou privés. 


\title{
Tungsten oxide thin film exposed to low energy He plasma: evidence for a thermal enhancement of the erosion yield
}

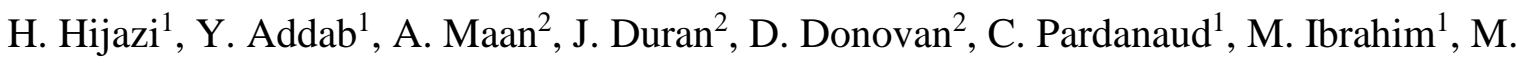 \\ Cabié $^{3}$, P. Roubin ${ }^{1}$ and C. Martin ${ }^{1 *}$ \\ ${ }^{1}$ Aix-Marseille Université, CNRS, PIIM UMR 7345, F-13397 Marseille, France \\ ${ }^{2}$ University of Tennessee-Knoxville, 1004 Estabrook Road, Knoxville, TN, 37996-2300, USA \\ ${ }^{3}$ Aix-Marseille Université, CP2M, F-13397 Marseille, France
}

\begin{abstract}
Nanocrystalline tungsten oxide thin films (about $75 \mathrm{~nm}$ in thickness) produced by thermal oxidation of tungsten substrates were exposed to low energy $\mathrm{He}$ plasma $(\approx 20 \mathrm{eV} / \mathrm{He})$ with a flux of $2.5 \times 10^{18} \mathrm{~m}^{-2} \mathrm{~s}^{-1}$ at two temperatures: room temperature and $673 \mathrm{~K}$. The structure and morphology modifications which occur after this He bombardment and annealing treatments was studied using Raman spectroscopy and transmission electron microscopy. Due to the low fluence $\left(4 \times 10^{21} \mathrm{~m}^{-2}\right)$ and low ion energy, we have observed only few morphology modifications after He plasma exposure at room temperature. On the contrary, at $673 \mathrm{~K}$, a change in the layer color is observed associated to an important erosion. Detailed analyses before/after exposure and before/after annealing allow us to describe the He interaction with the oxide layer, its erosion and structural modification at the atomic and micrometer scale.
\end{abstract}

Keywords: Tungsten oxide thin film, He plasma bombardment, erosion, plasma wall interaction, Raman spectroscopy, transmission electron microscopy.

*corrresponding author e-mail: celine.martin@univ-amu.fr 


\section{Introduction}

Because of its favorable physical properties, such as a high melting point and an excellent erosion resistance, tungsten $(\mathrm{W})$ is being used as plasma facing component (PFC) material for magnetic fusion devices such as the tokamaks ASDEX-Upgrade [1], ITER [2], JET [3] and WEST [4]. During the deuterium-tritium (D-T) fusion operation of ITER, significant helium (He) ash will be formed and will interact with the $\mathrm{W}$ divertor. Under plasma divertor conditions and even for impact energies below the physical sputtering threshold, which is estimated around $300 \mathrm{eV}$ [5], He ions have been found to cause erosion and redeposition or codeposition as well as significant morphology changes in W [6-10]. It should be noted that He ion bombardment has been found to have high affinity to create bubbles, holes and nanostructures. These Damages will change $\mathrm{W}$ physical and mechanical properties and this will change their interaction with plasma (such as: erosion rate, implantation and diffusion depth).

Various types of mixed materials can be formed during redeposition and codeposition processes in presence of impurities [11]. Oxygen can exist as contamination in tokamak vacuum vessels and W PFCs can be oxidized, this process being facilitated by the high temperatures reached during operation of the machine. Tungsten oxide can therefore be formed at the surface of tokamak PFCs with various stoichiometries $[11,12]$, the most stable being $\mathrm{WO}_{3}$, whose behavior in the tokamak environment is still not well known. Basically the tungsten oxide crystal $\mathrm{WO}_{3}$ is built up from corner-sharing $\mathrm{WO}_{6}$ octahedra, it easily forms substoichiometric shear phases $\left(\mathrm{WO}_{3-\mathrm{x}}\right)$ containing edge-sharing octaedra with various crystallographic structures.

Although many studies have been concerned with the consequences of $\mathrm{He}$ and $\mathrm{D}$ bombardments on $\mathrm{W}$ [5-10], only a few works have explored the behavior of $\mathrm{WO}_{3}$. The 
presence of an oxide layer can reduce the sputtering energy threshold of $\mathrm{W}$ by a factor of 10 , increase the erosion yield [13] and generate different hydrogen isotope retention mechanisms [14-16]. A. Pezzoli et al. [17] produced $\mathrm{WO}_{3}$ layers by the pulsed laser deposition technique in order to simulate redeposited layer compounds that can be present on PFCs. They have shown that the layer morphology and stoichiometry can be controlled by changing background $\mathrm{O}_{2}$ pressure during deposition. Surface modifications, such as nano-cracks, pinholes and bubbles, were observed after high flux $\left(10^{24} \mathrm{~m}^{-2} \mathrm{~s}^{-1}\right)$ D plasma exposure in Magnum-PSI at a layer temperature of $580 \mathrm{~K}$ [17]. Another study of tungsten oxide layers grown on polycrystalline ITER-grade surfaces by annealing in air for $10 \mathrm{~min}$ was carried out at various sample temperatures [18]. It has been shown that at low-energy (38 eV/D) and high flux $\left(10^{22} \mathrm{~m}^{-2} \mathrm{~s}^{-1}\right) \mathrm{D}$ plasma exposure (fluence of $10^{26} \mathrm{~m}^{-2}$ ), the formation of cracks appears for temperatures above $605 \mathrm{~K}$.

In a previous study, we have observed a color change and a phase transition of $\mathrm{WO}_{3}$ layers due to the formation of tungsten bronze $\left(\mathrm{D}_{\mathrm{x}} \mathrm{WO}_{3}\right)$ after a low energy $(\approx 20 \mathrm{eV})$ and low fluence $\left(4 \times 10^{21} \mathrm{~m}^{-2}\right)$ deuterium plasma exposure at room temperature [19]. This structural modification is due to $\mathrm{D}$ intercalation and deep diffusion into the $\mathrm{WO}_{3}$ channels and is reversible after a few days at ambient conditions.

In this work, the structural changes of $\mathrm{WO}_{3}$ layers under low energy $(\approx 20 \mathrm{eV})$ and low fluence $\left(4 \times 10^{21} \mathrm{~m}^{-2}\right)$ He plasma exposure at room temperature and $673 \mathrm{~K}$ was studied with the help of Raman spectroscopy and transmission electron microscopy. Our results emphasize an important effect of the sample temperature on these structural changes. 


\section{Experimental}

\section{1 $\mathrm{WO}_{3}$ thin film production}

Polycrystalline recrystallized tungsten (pc-W) samples produced by A.L.M.T. Corp., Japan (purity of $99.99 \%$ ), measuring $7 \times 7 \times 0.3 \mathrm{~mm}$, were used as substrates for growing oxide layers. The $\mathrm{W}$ grain size was found to be a few tens of micrometers using scanning electron microscopy (SEM) (Microscope Philips XL30 SFEG, Schottky Field Emission Gun). The pc-W substrates were outgassed at $10^{-7}$ torr and $673 \mathrm{~K}$ during 4 hours. Afterwards, thermal oxidation at $673 \mathrm{~K}$ on the pc-W substrates was performed at oxygen pressure of 590 torr during 90 min. Thanks to this procedure, we produced a set of identical $\gamma-\mathrm{WO}_{3}$ (referred to $\mathrm{WO}_{3}$ hereafter) samples whose structure was monoclinic and nanocrystalline, as confirmed by X-rays diffraction analysis (not shown in this paper). The oxide layer thickness, measured using a FIB cross-section technique (FEI Helios 600 NanoLab Dual Beam), was about $75 \pm 4 \mathrm{~nm}$. The corresponding oxide layer color was blue.

Raman spectra were recorded using a Horiba-Jobin-Yvon HR LabRAM microscope $(\lambda=$ $514 \mathrm{~nm}$ and $532 \mathrm{~nm}$, laser spot size $\approx 1 \mu \mathrm{m}^{2}$ ). The laser power was kept at about $1 \mathrm{~mW} \mu \mathrm{m}^{-2}$. The Raman mapping mode was used to average 30 spectra collected over a $750 \mu \mathrm{m}^{2}$ area in order to increase the signal to noise ratio and to detect eventual inhomogeneities. Spectra were measured in the Raman shift range of $100-1250 \mathrm{~cm}^{-1}$. Transmission Electron Microscopy (TEM) (FEI Tecnai G2 - thermo-ionic $\mathrm{LaB}_{6}$ electron source - accelerated voltage $200 \mathrm{kV}$ ) was used for the structural analysis of the oxide layer and oxide/tungsten interface on $\sim 100 \mathrm{~nm}$ slices cut perpendicular to the sample surface by Focused Ion Beam (FIB) technique. 


\subsection{Plasma exposure stage}

The University of Tennessee Nuclear Engineering (UTNE) ion exposure stage utilizes a PCS-ECR Plasma Cracker Source manufactured by SPECS Surface Nano Analysis GmbH, which is a compact electron cyclotron resonance (ECR) ion source (fig 1) [20]. This experiment is similar in design and purpose to the ion exposure stage utilized at Sandia National Laboratory, which demonstrated the capability to produce He bubble growth in heated W samples using a compact ECR ion source [21]. The UTNE source operates with helium or other inert gases and is equipped with a molybdenum extraction grid able to be biased up to $-1000 \mathrm{~V}$ to accelerate the ions to the desired energy. The He ion flux used during exposures was kept at approximately $2.5 \times 10^{18} \mathrm{~m}^{-2} \mathrm{~s}^{-1}$ at the sample face (with a corresponding current $\approx 20$ $\mu \mathrm{A})$. The $\mathrm{W}$ samples were mounted on a pyrolytic boron nitride (PBN) plate heater manufactured by Momentive Performance Materials, which was capable of heating samples to temperatures up to approximately $1300 \mathrm{~K}$.

The sample was held in place on the heater stage with the PBN plate that also controlled the exposed area (fig 2). The sample holder was mounted on a linear motion vacuum feedthrough in the sample loading chamber. The sample loading chamber could then be sealed and pumped down to several millitorr, allowing the gate valve separating the plasma exposure chamber and the sample loading chamber to be opened. The linear motion feedthrough then allowed the sample to be inserted into the ion exposure chamber and brought to within $4 \mathrm{~cm}$ of the exit aperture of the ion source.

The base pressure in the ion exposure chamber was about $2.2 \times 10^{-5}$ torr before the exposure. In the case of the exposure at $673 \mathrm{~K}$, the sample was heated up slowly during 90 min to reach $673 \mathrm{~K}$ with a pressure in the chamber around $1.3 \times 10^{-5}$ torr, remaining at around $9.4 \times 10^{-4}$ torr during the exposure at room temperature and $673 \mathrm{~K}$. Table 1 summarizes the experimental 
conditions the four identical $\mathrm{WO}_{3}$ layers: (i) $\mathrm{WO}_{3}$ as oxidized was used as a reference, (ii) $\mathrm{WO}_{3}-673 \mathrm{~K}$ was annealed in a vacuum chamber at $673 \mathrm{~K}$ during 2 hours at $7.5 \times 10^{-6}$ torr, (iii) $\mathrm{WO}_{3}-\mathrm{HeRT}$ and (iv) $\mathrm{WO}_{3}-\mathrm{He} 673 \mathrm{~K}$ were exposed to $20 \mathrm{eV}$ He plasma with a fluence of $4 \times 10^{21}$ $\mathrm{m}^{-2}$ (exposure time of $27 \mathrm{~min}$ ) at room temperature and $673 \mathrm{~K}$, respectively.

\section{Results and Discussions}

\subsection{Annealing effect}

Figure 3 shows the Raman spectra of as oxidized $\mathrm{WO}_{3}\left(\mathrm{WO}_{3}\right.$, in blue) and $\mathrm{WO}_{3}$ annealed at $673 \mathrm{~K}\left(\mathrm{WO}_{3}-673 \mathrm{~K}\right.$, in red) in the $100-1100 \mathrm{~cm}^{-1}$ region and normalized to the intensity of the main peak at $807 \mathrm{~cm}^{-1}$. In the literature, the monoclinic structure is identified by two bands peaking in the range $700-720 \mathrm{~cm}^{-1}$ and $805-808 \mathrm{~cm}^{-1}$ in the stretching mode region (500-900 $\mathrm{cm}^{-1}$ ) and in the range $128-135 \mathrm{~cm}^{-1}$ and $268-275 \mathrm{~cm}^{-1}$ in the bending mode region (100-500 $\mathrm{cm}^{-1}$ ) [22-24]. The features found here at $703 \mathrm{~cm}^{-1}, 807 \mathrm{~cm}^{-1}$ and $130 \mathrm{~cm}^{-1}, 270 \mathrm{~cm}^{-1}$ confirm the monoclinic structure of the sample as previously identified by XRD. The shoulder observed at $645 \mathrm{~cm}^{-1}$ is attributed to oxide hydratation while the shoulder observed at $960 \mathrm{~cm}^{-1}$ is attributed to terminal $\mathrm{W}=\mathrm{O}$ stretching modes and reveals the presence of defects in the crystalline monoclinic structure. As the sample structure is nano-crystalline (see figure 6), these defects may be due to grain boundaries, in agreement with previous observations relating terminal $\mathrm{W}=\mathrm{O}$ stretching modes to the presence of nano-grains [25]. Raman spectra of $\mathrm{WO}_{3}$ as oxidized and $\mathrm{WO}_{3}$ annealed are very similar, with no evidence for a phase reorganization: the monoclinic structure of the $\mathrm{WO}_{3}$ layer is thus clearly not modified after annealing at $673 \mathrm{~K}$. The slight decrease of the shoulder at $645 \mathrm{~cm}^{-1}$ could be attributed to the dehydration of the $\mathrm{WO}_{3}$ layer $[26,27]$. 
Figure 4 shows a TEM image of $\mathrm{WO}_{3}-673 \mathrm{~K}$ taken from a slice prepared by FIB. The oxide layer is compact and the tungsten/oxide interface is smooth and well defined. The layer thickness has not changed, still measured at $75 \pm 4 \mathrm{~nm}$ after annealing. Both the interface and the top surface (protected by a Pt coating during the FIB preparation) do not show any significant changes after annealing.

To conclude, Raman spectroscopy and TEM results show that neither the thickness nor the nano-crystalline structure of the initial $\mathrm{WO}_{3}$ layer change after a thermal treatment at $673 \mathrm{~K}$.

\subsection{He plasma exposure}

Figure 5 shows photographs of $\mathrm{WO}_{3}, \mathrm{WO}_{3}-\mathrm{HeRT}$ and $\mathrm{WO}_{3}-\mathrm{He} 673 \mathrm{~K}$ samples. After He plasma exposure at room temperature ( $\mathrm{WO}_{3}-\mathrm{HeRT}$ sample), the sample color has not changed while, on the contrary, after He exposure at $673 \mathrm{~K}$ ( $\mathrm{WO}_{3}-\mathrm{He} 673 \mathrm{~K}$ sample), the sample color turned to orange, this color change being not reversible with time.

No color change was noticed on $\mathrm{WO}_{3}$ heated at $673 \mathrm{~K}$ without bombardment, and therefore excluding an effect due to the temperature alone. As, due to interference phenomena, oxide layers with different thicknesses may have different colors [19], this change could be explained by a change in the thickness of $\mathrm{WO}_{3}-\mathrm{He} 673 \mathrm{~K}$.

It is worthwhile to mention that SEM images (not shown here) show that the $\mathrm{He}$ bombardment has no effect on the surface of the oxide layer, without any evidence of morphological modifications such as nano-cracks or point-like features. This was expected as exposures were done at very low fluences $\left(\approx 4 \times 10^{21} \mathrm{~m}^{-2}\right)$ while such modifications were observed in $[17,18,28]$ with much higher fluences $\left(\approx 10^{26} \mathrm{~m}^{-2}\right)$. In what follows, we detail TEM analyses aimed at studying the He bombardment effects in the sub-surface and in the bulk of the oxide layer. 
Figure 6 shows TEM images of the $\mathrm{WO}_{3}$ layer exposed at room temperature $\left(\mathrm{WO}_{3}-\mathrm{RT}\right.$ sample). The surface is smooth and the oxide/tungsten interface is smooth and well defined as previously shown for $\mathrm{WO}_{3}-673 \mathrm{~K}$ (fig 4). The thickness of the oxide layer is measured at $71 \pm 4$ $\mathrm{nm}$ (fig 6a). Comparing this value to the original thickness ( $75 \pm 4 \mathrm{~nm}$ ), we notice no significant change in thickness and hence no significant erosion.

On the contrary, TEM images of exposed $\mathrm{WO}_{3}$ at $673 \mathrm{~K}$ (WO3-He673K sample) shows significant damage and the formation of new features at the interface (fig 7). First, the oxide layer thickness is now measured at $54 \pm 5 \mathrm{~nm}$ (fig 7a): a decrease in thickness of about $21 \mathrm{~nm}$ which corresponds to an erosion rate of about $0.013 \mathrm{~nm} \mathrm{~s}^{-1}$. Assuming a layer density of $7.16 \mathrm{~g}$ $\mathrm{cm}^{-3}$, we thus estimate tungsten oxide sputtering yield $\mathrm{Y}_{\mathrm{s}}$ at $0.10 \pm 0.05$ at $673 \mathrm{~K}$. Second, the presence of interference fringes in the TEM image of fig $7 \mathrm{~b}$ shows that the bulk of the layer (beyond $10 \mathrm{~nm}$ ) is still crystallized. Nevertheless, the oxide sub-surface (fig $7 \mathrm{~b}$ ) shows the presence of a $10 \mathrm{~nm}$ thick modified layer which appears to be darker on the image. This darker contrast reveals a higher density due to a loss of oxygen which can be preferentially sputtered. This has also been reported in [17] and has been already observed for oxide materials in other applications [29].

The oxide layer is not homogeneous anymore and in order to better identify the nature of this $10 \mathrm{~nm}$ surface layer we have performed Raman analysis using a UV laser wavelength $(\lambda=325 \mathrm{~nm})$ (figure 8 ). This allows only the damaged surface layer to be probed, without penetrating into the bulk. Figure 8 shows the normalized Raman spectra of $\mathrm{WO}_{3}-\mathrm{HeRT}$ (blue) and $\mathrm{WO}_{3}-\mathrm{He} 673 \mathrm{~K}$ (red) in the stretching mode region $\left(500-1100 \mathrm{~cm}^{-1}\right)$. The Raman spectrum of $\mathrm{WO}_{3}-\mathrm{He} 673 \mathrm{~K}$ is broadened and the two main peaks of the monoclinic $\gamma-\mathrm{WO}_{3}$ are not separated anymore. This typical broad band feature is a signature of amorphous tungsten oxide (a-WO3) $[17,30]$. 
Finally, fig 7a shows that the oxide/tungsten interface is highly damaged and reveals the formation of voids. These damages cannot be related only to a temperature effect as we have previously shown (fig 4) and are due to the He bombardment. This shows that He has diffused throughout the oxide layer, and that the clustering of trapped He has formed bubbles.

Raman analyses performed at $\lambda=532 \mathrm{~nm}$ for which the layer is transparent allow us to deepen the understanding of the structural modification of the entire layer. In fig 9, the normalized Raman spectra of $\mathrm{WO}_{3}$ (black), $\mathrm{WO}_{3}-\mathrm{HeRT}$ (blue) and $\mathrm{WO}_{3}-\mathrm{He} 673 \mathrm{~K}$ (red) are reported in the stretching mode region (500-1100 $\left.\mathrm{cm}^{-1}\right)$. Compared with $\mathrm{WO}_{3}$, the Raman intensity (integrated area) has decreased by a factor of 1.3 for $\mathrm{WO}_{3}-\mathrm{HeRT}$ and by a factor of 3.9 for $\mathrm{WO}_{3}-\mathrm{He} 673 \mathrm{~K}$. The main peaks of the monoclinic structure are observed for the three samples although they are broadened after exposition, this broadening being larger at $673 \mathrm{~K}$ than at room temperature, indicating the creation of defects and thus an increase of the local disorder. This disorder can be represented by the distortion of the $\mathrm{WO}_{6}$ octahedrons which compose the monoclinic $\mathrm{WO}_{3}$ structure. The creation of disorder is confirmed by the increase of the relative intensity of the $703 \mathrm{~cm}^{-1}$ and $960 \mathrm{~cm}^{-1}$ peaks with respect to that of the main peak at $807 \mathrm{~cm}^{-1}$ and the increase of the relative intensity between bending and stretching mode bands (not shown here). The peak at $807 \mathrm{~cm}^{-1}$ is blue-shifted to $810 \mathrm{~cm}^{-1}$ and $826 \mathrm{~cm}^{-1}$ for $\mathrm{WO}_{3}-\mathrm{HeRT}$ and $\mathrm{WO}_{3}-\mathrm{He} 673 \mathrm{~K}$, respectively. This shift is consistent with a shortening of $\mathrm{W}-\mathrm{O}$ bonds due to (i) the formation of oxygen vacancies, (ii) a compressive stress introduced by trapped He and (iii) the breaking of WO bonds.

Note that the Raman spectra show that all the entire layer is affected by these changes and therefore that there He diffuses throughout the oxide layer. 


\subsection{Discussion}

Annealing at $673 \mathrm{~K}$ does not produce significant structural modification, and in particular does not increase the lattice organization: this is not very surprising as this temperature was used for the oxide layer production and this shows that the sample structure is not altered even after several weeks under air.

Exposing the tungsten oxide layer at room temperature with a fluence of $4 \times 10^{21} \mathrm{~m}^{-2}$ of $20 \mathrm{eV}$ He ions did not introduce any damage at the oxide/tungsten interface or erosion: this latter observation is in agreement with Roth et al. [13] which, when tungsten oxide is produced during exposition with $\mathrm{He}$ ions under background oxygen pressure of $8 \times 10^{-5}$ torr, has extrapolated the sputtering energy threshold by He below $10 \mathrm{eV}$. In our case, the ion energy is $20 \mathrm{eV}$ and the expected sputtering yield is about $7 \times 10^{-4} \mathrm{WO}_{3} / \mathrm{He}$ [13], which would correspond to a decrease in thickness of $0.15 \mathrm{~nm}$, much less than our thickness measurement precision. No noticeable structural modification at the microscale is observed and the monoclinic nano-crystalline structure is still well characterized by Raman spectroscopy. Nevertheless, the introduction of local disorder is identified which could be represented by an increase of the disorder of the octahedral $\mathrm{O}$ structure surrounding $\mathrm{W}$ atoms generated by the formation of oxygen vacancies subsequently to collisions, by the compressive stress induced by the trapped He or by breaking of WO bonds.

Unlike this He bombardment, a previous study has shown the D bombardment of a similar oxide layer under similar plasma conditions [19] leads to the change of the layer color (blue to orange), this coloration effect being reversible. This D plasma chromic effect is similar to the extensively studied electrochromic effect of $\mathrm{WO}_{3}$ where the ion diffusion and intercalation is induced by the application of an electrical voltage. In both cases, a coloration is observed which is due to the formation of $\mathrm{D}_{\mathrm{x}} \mathrm{WO}_{3}$ bronze by $\mathrm{D}^{+}$intercalation and diffusion throughout the $\mathrm{WO}_{3}$ 
layer. Even though if, as D, He ions diffuse, intercalate and induce local disorder, unlike D, He does not lead to chemical reactivity and to bronze formation.

On the contrary, major changes such as bubble or void formations at the oxide / tungsten interface are observed when exposing the oxide layer at $673 \mathrm{~K}$ at similar plasma conditions. In the case of pure tungsten, these morphology changes have been already observed for higher He energy on tungsten at surface temperature ranging 673-1273 K [6-10]. While still not completely understood, they are thought to result from near-surface He trapping at intrinsic or extrinsic defect sites. Due to low He solubility in tungsten, the trapped He atoms form clusters, which result in progressively higher lattice distortions, which relax by dislocation loop punching, producing He-filled cavities (bubbles) of increasing size. Here, both the diffusion of He throughout the film and the thermal activation of the cluster formation at the interface can explain the bubbles we observed at $673 \mathrm{~K}$.

Contrary to what is observed at room temperature, a significant film thickness decrease by $21 \pm 5 \mathrm{~nm}$ is observed at $673 \mathrm{~K}$ that we attribute to erosion. This is the first time that such a sputtering effect is observed for helium at low energy. The only experimental study previously published on the sputtering of tungsten oxide by low energy He ions was that of Roth et al. [13] at room temperature. As an example of temperature effect, we can mention the sputtering of tungsten oxide by $150 \mathrm{eV}-10 \mathrm{keV}$ oxygen ion beams studied in [31] where it was found that the yield increases by increasing the target temperature. In another study, the sputtering yield and the roughness of $\mathrm{W}$ layers irradiated by $\mathrm{He}$ ions at various energies and various temperatures have been studied by Yunfeng Wu et al. [32]. It was found that, for He ion energy of $300 \mathrm{eV}$, the $\mathrm{W}$ sputtering yield increases from $4.06 \times 10^{-3} \mathrm{WO}_{3} / \mathrm{He}$ at $\mathrm{T}=293 \mathrm{~K}$ to $1.44 \times 10^{-2}$ $\mathrm{WO}_{3} / \mathrm{He}$ at $973 \mathrm{~K}[32]$. Although the sputtering mechanisms are not yet fully understood, our study clearly shows that the combination of He bombardment and surface heating induce a sputtering effect. A possible scenario is that He ion bombardment breaks bonds allowing 
weakly bounded $\mathrm{W}_{\mathrm{x}} \mathrm{O}_{\mathrm{y}}$ molecules to be produced in the sub-surface whose release into the gas phase is thermally driven. Assuming that this loss corresponds to a $\mathrm{WO}_{3}$ sputtered layer whose density is $7.14 \mathrm{~g} / \mathrm{cm}^{3}$, we estimate the sputtering yield of $\mathrm{WO}_{3}$ at about $0.10 \pm 0.05 \mathrm{WO}_{3} / \mathrm{He}$.

We have shown the formation of $10 \mathrm{~nm}$ damaged sub-surface layer which is deficient in oxygen and most likely highly disordered, and which may correspond to the region of collision cascades. We have demonstrated that this damaged layer is an amorphous tungsten oxide $\left(\mathrm{a}-\mathrm{WO}_{3}\right)$. An example of similar sub-surface damages exceeding the implantation zone due to low energy ion implantation was the amorphisation of a $30 \pm 10 \mathrm{~nm}$ carbon layer observed using similar methods (FIB/TEM) for the eroded graphite surface of the Tore Supra tokamak [33]. Here there is no clear sign that the modified layer has become completely amorphous but it is probably highly deficient in oxygen and probably a key region to explore to understand the sputtering mechanisms

\section{Conclusion}

Nanocrystalline tungsten oxide $\mathrm{WO}_{3}$ thin films produced by thermal oxidation on tungsten substrate were exposed to low energy He plasma $(\approx 20 \mathrm{eV} / \mathrm{He})$ with a flux of $2.5 \times 10^{18} \mathrm{~m}^{-2} \mathrm{~s}^{-1}$ at a fluence of $4 \times 10^{21} \mathrm{~m}^{-2}$ at two different temperatures: room temperature and $673 \mathrm{~K}$. In both cases, defect formation (local disorder introduced by oxygen vacancies, compressive stress or by WO breaking bonds) changes the Raman signature of the oxide film, whereas the nano-crystalline structure of the film remain unaltered. We have shown that, when activated by temperature, exposure of the tungsten oxide with low energy He ions leads to erosion: although no sputtering is observed at room temperature, we have measured a sputtering yield of $0.10 \pm$ $0.05 \mathrm{WO}_{3} / \mathrm{He}$ at $673 \mathrm{~K}$. We have put in evidence that the sub-surface was disordered and oxygen deficit can be likely explained by preferential sputtering of oxygen. We have observed 
the formation of voids at the $\mathrm{WO}_{3} / \mathrm{W}$ interface which could be the consequence of $\mathrm{He}$ implanted in the sub-surface layer followed by thermal diffusion of $\mathrm{He}$ atoms throughout the film and their clustering. Further studies are necessary to analyse the role of temperature in the activation of the mechanisms at play in the erosion processes.

\section{Acknowledgements}

This work has been carried out within the framework of EUROfusion Consortium and has received funding from the Euratom research and training programme 2014-2018 under grant agreement No 633053. The views and opinions expressed herein do not necessarily reflect those of the European Commission. Research was supported as well by the A*MIDEX project (no ANR-11-IDEX-0001-02) sponsored by the 'Investissements d'Avenir' French Government program, managed by the French National Research Agency (ANR). We would like to thank the The University of Tennessee Nuclear Engineering (UTNE) - Knoxville where the experiments were carried out. 


\section{References}

[1] K. Sugiyama, M. Mayer, V. Rohde, M. Balden, Th. Dürbeck, A. Herrmann, S. Lindig, A. Wiltner, H.W. Müller, R. Neu, Nucl. Fusion 50 (2010) 035001

[2] G. Federici, P. Andrew, P. Barabaschi, J. Brooks, R. Doerner, A. Geier, A. Herrmann, G. Janeschitz, K. Krieger, A. Kukushkin, A. Loarte, R. Neu, G. Saibene, M. Shimada, G. Strohmayer, M. Sugihara, J. Nucl. Mater. 313-316 (2003) 11-22.

[3] G. Ritz, T. Hirai, P. Norajitra, J. Reiser, R. Giniyatulin, A. Makhankov, I. Mazu, G. Pintsuk and J. Linke, Phys. Scr. T138 (2009) 014064 (5pp)

[4] C. Bourdelle et al., Nucl. Fusion 55 (2015) 063017.

[5] W. Eckstein, C. Garci-Rosales, J. Roth, and J. Lsz, Nucl. Instrum. Methods Phys. Res. B 83(12) (1993) $95-109$.

[6] H. Iwakiri, K. Yasunaga, K. Morishita, N. Yoshida, J. Nucl. Mater. 283 (2000) 1134.

[7] F. W. Meyer, H. Hijazi, M. E. Bannister, P. S. Krstic, J. Dadras, H. M. Meyer III and C. M. Parish, Phys. Scr. T159 (2014) 014029.

[8] D. Nishijima, M.Y. Ye, N. Ohno, S. Takamuraa, J. Nucl. Mater. 313 (2003) 97.

[9] M.J. Baldwin, T.C. Lynch, R.P. Doerner, J.H. Yu, J. Nucl. Mater. 415 (2011) S104.

[10] M. Yamagiwa, S. Kajita, N. Ohno, M. Takagi, N. Yoshida, R. Yoshihara, W. Sakaguchi, H. Kurishita, J. Nucl. Mater. 417 (2011) 499.

[11] J. P. Coad, E. Alves, N. P. Barradas, A. Baron-Wiechec, N. Catarino, K. Heinola, J. Likonen, M. Mayer, G. F. Matthews, P. Petersson, Phys. Scr. T159 (2014) 014012.

[12] R. Neu, Ch. Hopf, A. Kallenbach, T. Pütterich, R. Dux, H. Greuner, O. Gruber, A. Herrmann, K. Krieger, H. Maier, V. Rohde, J. Nucl. Mater. 367-370 (2007) 1497. 
[13] J. Roth, J. Bohdansky, W. Ottenberger, Data on Low Energy Light Ion Sputtering, Report IPP 9/26, Max-Planck-Institut für Plasmaphysik, Garching, 1979.

[14] A. Inouye, S. Yamamoto, S. Nagata, M. Yoshikawa, T. Shikama. Nucl. Instrum. Methods Phys. Res. B 267 (2009) 1480.

[15] S. Nagata and K. Takahiro, Phys. Scr. T94 (2001)106.

[16] V. Kh Alimov, V. M. Sharapov, Phys. Scr. T103 (2003) 72.

[17] A. Pezzoli, D. Dellasega, V. Russo, A. Gallo, P.A. Zeijlmans van Emmichoven, M. Passoni, J. Nucl. Mater. 463 (2015) 1041-1044

[18] V.K. Alimov, B. Tyburska, M. Balden, S. Lindig, J. Roth, K. Isobe, T. Yamanishi, J. Nucl. Mater. 409 (2011) 27-32

[19] Y. Addab, C. Martin, C. Pardanaud, J. Khayadjian, K. Achkasov, D. Kogut, G. Cartry, G. Giacometti, M. Cabié, J. L. Gardarein and P. Roubin, Phys. Scr. T167 (2016) 014036 [20] http://www.specs.de/cms/front_content.php?idcat=108

[21] D. Donovan, D. Buchenauer, J. Whaley and R. Friddle, Phys. Scr. T167 (2016) 014040

[22] F. D. Hardcastle, I. E. Waches, J. Raman Spectrosc. 26, (1995) 397-405.

[23] D. Davazoglou, A. Donnadieu, R. Fourcade, A. Hugot-Legoff, P. Delichère et A. Perez, Revue Phys. Appl. 23 (1988) 265-272.

[24] E. Cazzanelli, C. Vinegoni, G. Mariotto, A. Kuzmin and J. Purans, J. Solid State Chem. 143 (1999) 24-32.

[25] C. Ingram Vargas-Consuelos, Kyungah Seo, Marco Camacho-López, and Olivia A. Graeve, J. Phys. Chem. C, 118 (18) (2014) 9531-9537

[26] M.F. Daniel, B. Desbat, J.C. Lassegues, J.Solid State Chem. 67 (1987) 235-247.

[27] C. Santato, M. Odziemkowski, M. Ulmann, and J. Augustynski, J. Am. Chem. Soc. 123 (2001) 10639. 
[28] S. Kajita, A. Ohta, T. Ishida, K. Makihara, T. Yoshida, N. Ohno, Jap. J. App. Phys. 54, (2015) 126201.

[29] R. E. Johnson, R. Baragiola, Geophys. Res. Lett. 18 (1991) 2169.

[30] F. Di Fonzo, A. Bailini, V. Russo, A. Baserga, D. Cattaneo, M.G. Beghi, P.M. Ossi, C.S. Casari, A. Li Bassi, C.E. Bottani, Catal. Today 116 (2006) 69.

[31] E. Hechtl, W. Eckstein, J. Roth, J. Laszlo, J. Nucl. Mater. 179-181 (1991) 290.

[32] W. Yunfeng, N. Weiyuan, F. Hongyu, L. Lu, Y. Qi, C. Baosheng, L. Dongping, J. Nucl. Mater. 470 (2016) 164.

[33] C. Martin, R. Ruffe, C. Pardanaud, M. Cabié, C. Dominici, T. Dittmar, P. Languille, B. Pégourié, E. Tsitrone, P. Roubin, J. Nucl. Mater. 415 (2011) 258. 


\section{Figure Captions}

Figure 1: UTNE ion exposure stage with the compact ECR ion source. Samples are loaded in the right chamber (Sample Loading Chamber) and then transferred through a gate valve to the left chamber (Ion Exposure Chamber) using a linear motion feedthrough for exposure to He plasma generated in the ECR ion source.

Figure 2: Square tungsten oxide sample mounted on the heater stage held in place with the polycrystalline boron nitride face plate.

Figure 3: Raman spectra of as oxidized $\mathrm{WO}_{3}$ (blue) and annealed $\mathrm{WO}_{3}$ at $673 \mathrm{~K}$ during 2 hours $\mathrm{WO}_{3}-673 \mathrm{~K}$ ( red). Spectra were measured using $\lambda=532 \mathrm{~nm}$.

Figure 4: TEM image of a FIB cross-section of annealed $\mathrm{WO}_{3}$ at $673 \mathrm{~K}$ during 2 hours $\left(\mathrm{WO}_{3}-673 \mathrm{~K}\right)$.

Figure 5: Photographs of tungsten oxide films: (a) $\mathrm{WO}_{3}$, (b) $\mathrm{WO}_{3}-\mathrm{HeRT}$ and (c) $\mathrm{WO}_{3}-\mathrm{He} 673 \mathrm{~K}$.

Figure 6: (a) TEM image of $\mathrm{WO}_{3}$ film exposed to $\mathrm{He}$ at $\mathrm{RT}\left(\mathrm{WO}_{3}-\mathrm{HeRT}\right)$ and (b) high resolution TEM image of the zone indicated in the square in (a) showing the nanocrystalline structure of $\mathrm{WO}_{3}-\mathrm{HeRT}$.

Figure 7: (a) TEM image of $\mathrm{WO}_{3}$ film exposed to $\mathrm{He}$ at $673 \mathrm{~K}\left(\mathrm{WO}_{3}-\mathrm{He} 673 \mathrm{~K}\right)$ and (b) high resolution TEM image showing the formation of a darker layer on the oxide surface.

Figure 8: Raman spectra of $\mathrm{WO}_{3}-\mathrm{HeRT}$ (blue) and $\mathrm{WO}_{3}-\mathrm{He} 673 \mathrm{~K}$ (red) samples. Spectra were measured using $\lambda=325 \mathrm{~nm}$ (UV laser). 
Figure 9: Raman spectra of $\mathrm{WO}_{3}$ (black), $\mathrm{WO}_{3}-\mathrm{HeRT}$ (blue) and $\mathrm{WO}_{3}-\mathrm{He} 673 \mathrm{~K}$ (red) samples. Spectra were measured using $\lambda=532 \mathrm{~nm}$.

Table 1: Experimental conditions of the four tungsten oxide samples: reference oxide $\mathrm{WO}_{3}$, annealed oxide $\mathrm{WO}_{3}-673 \mathrm{~K}$, oxide exposed to $\mathrm{He}$ plasma at $300 \mathrm{~K} \mathrm{WO}_{3}-\mathrm{HeRT}$, and oxide exposed to He plasma at $673 \mathrm{~K} \mathrm{WO}_{3}-\mathrm{He} 673 \mathrm{~K}$.

\begin{tabular}{|c|c|c|}
\hline & Sample & Experimental conditions \\
\hline \multirow{2}{*}{ Unexposed } & $\mathrm{WO}_{3}$ & As oxidized \\
\hline & $\mathrm{WO}_{3}-673 \mathrm{~K}$ & Annealed at $673 \mathrm{~K}$ for 2 hours \\
\hline \multirow[b]{2}{*}{ Exposed } & $\mathrm{WO}_{3}-\mathrm{HeRT}$ & Room Temperature $\approx 20 \mathrm{eV}$ \\
\hline & $\mathrm{WO}_{3}-\mathrm{He} 673 \mathrm{~K}$ & $673 \mathrm{~K} \quad \begin{array}{ll}\approx 2.5 \times 10^{18} \mathrm{~m}^{-2} \mathrm{~s}^{-1} \\
4 \times 10^{21} \mathrm{~m}^{-2}\end{array}$ \\
\hline
\end{tabular}




\section{FIGURES}

Figure 1

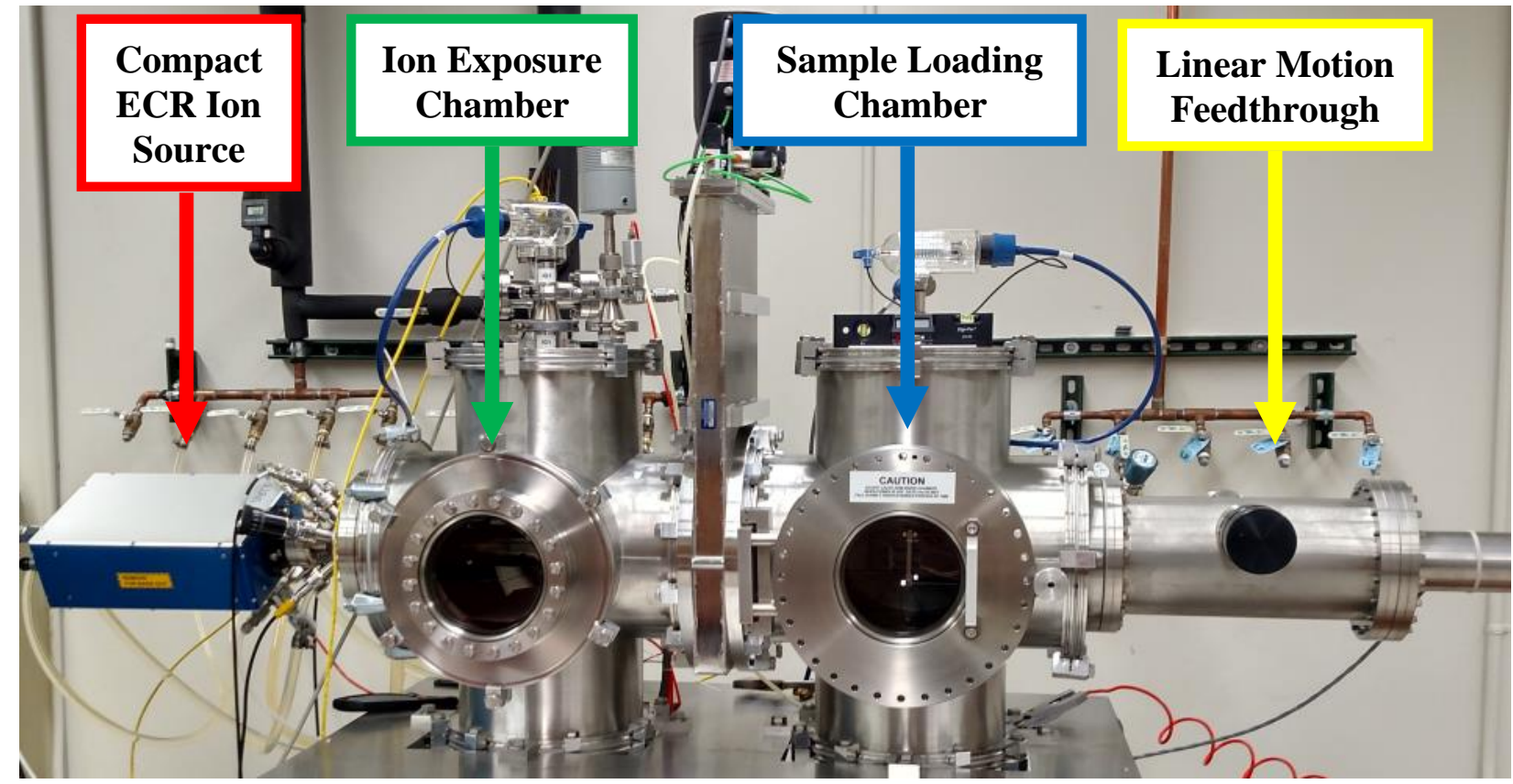

Figure 2

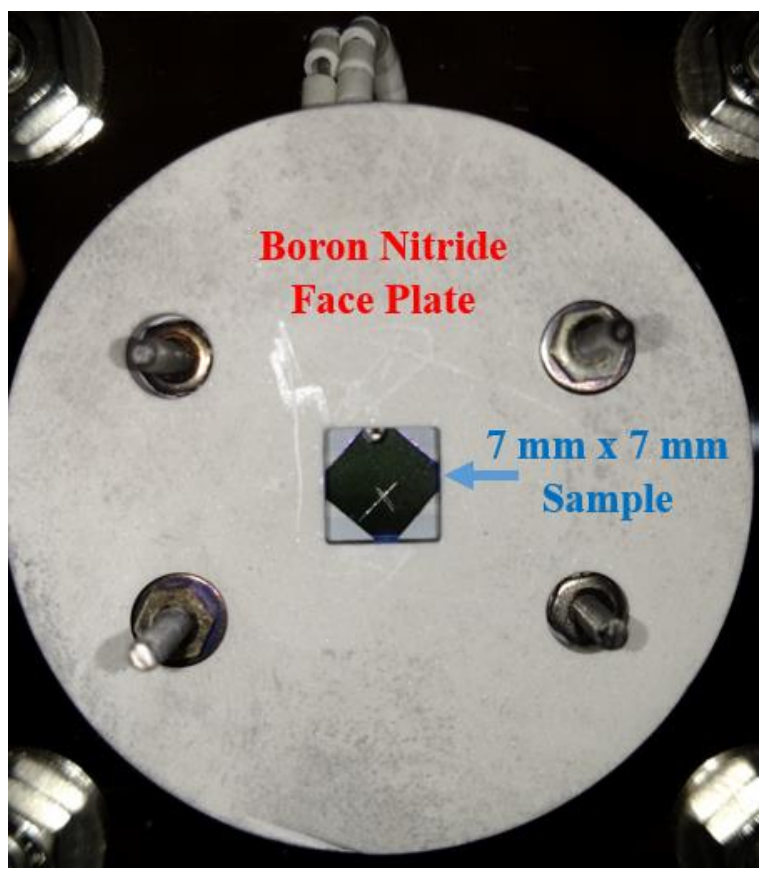


Figure 3

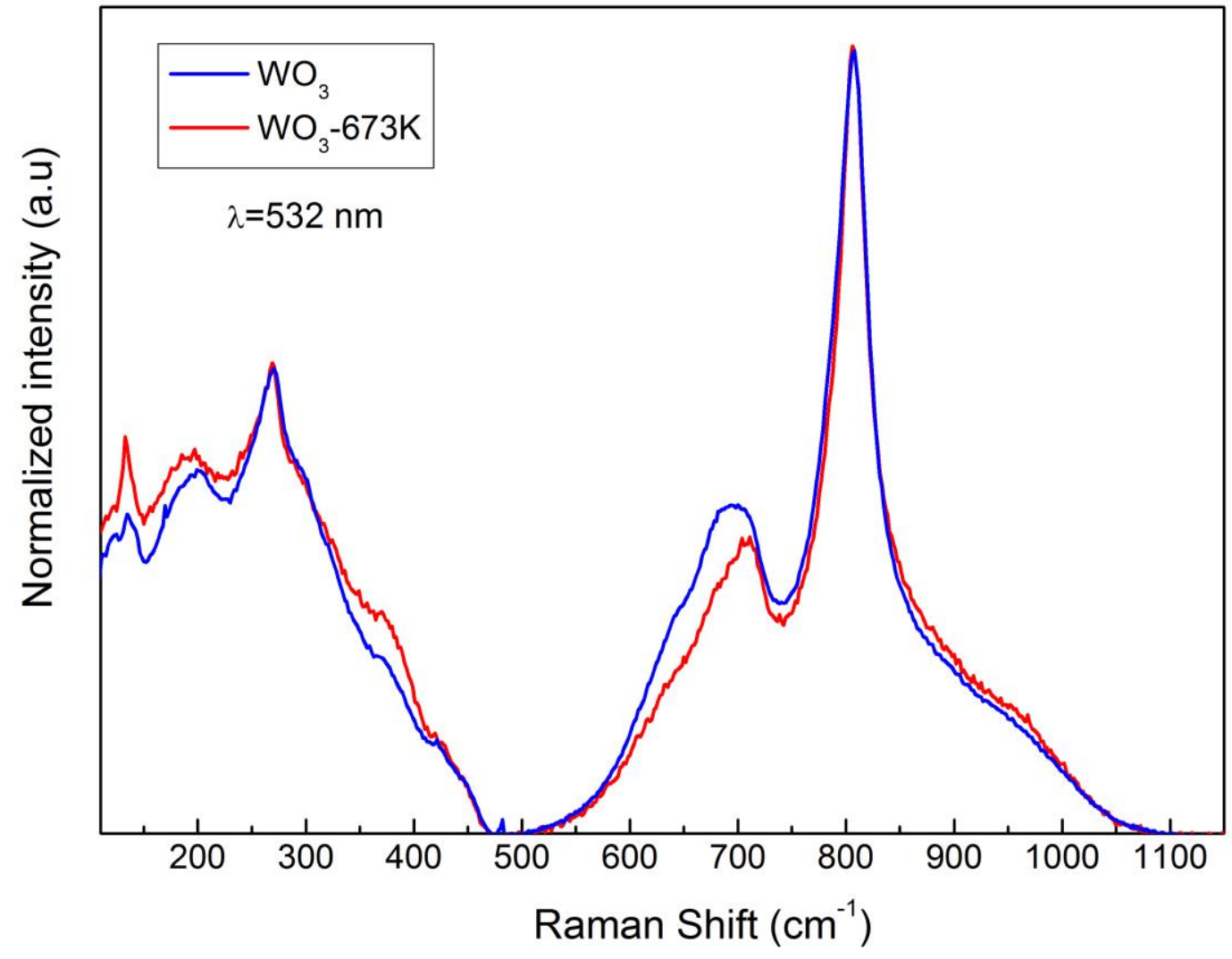


Figure 4

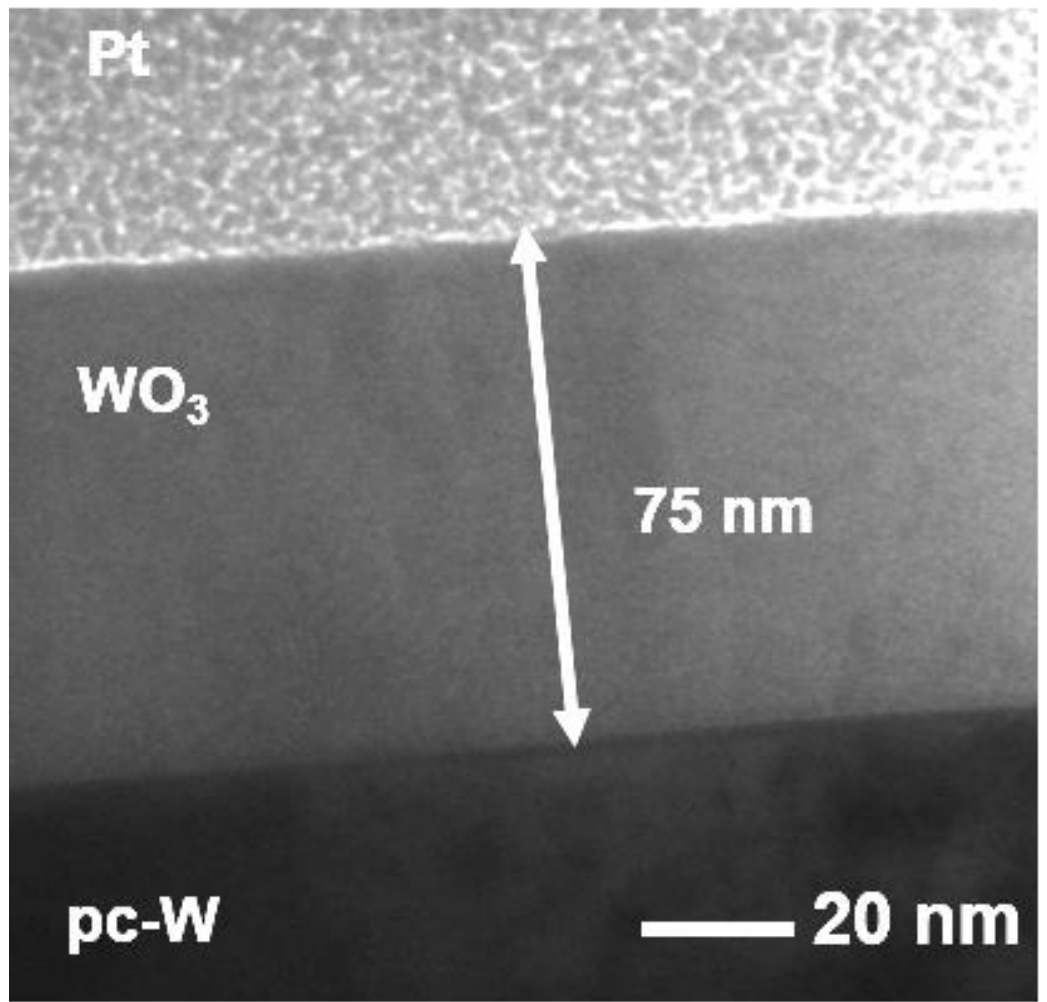

Figure 5

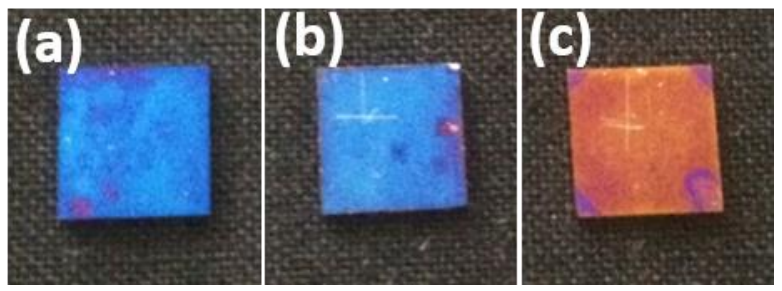


Figure 6
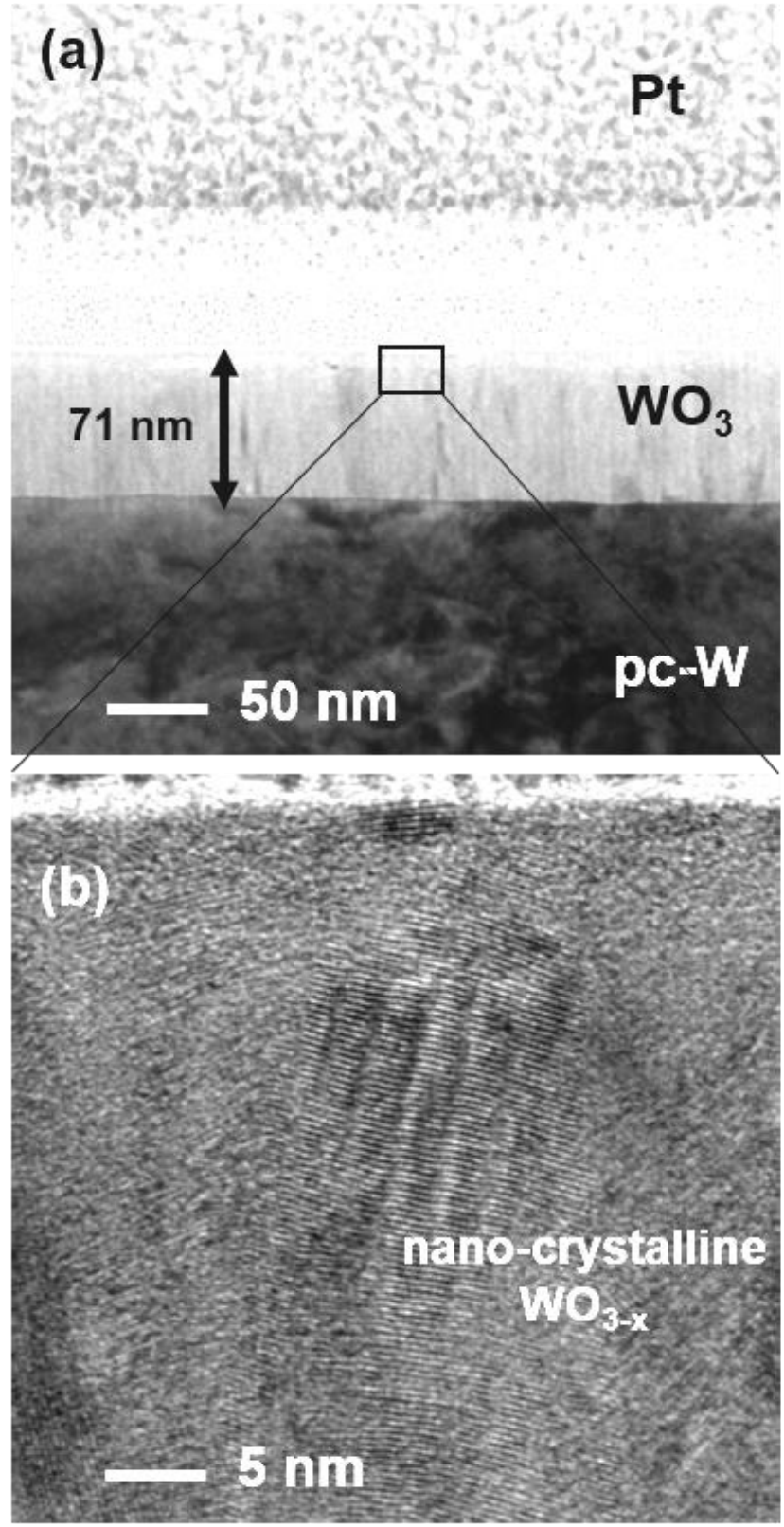
Figure 7
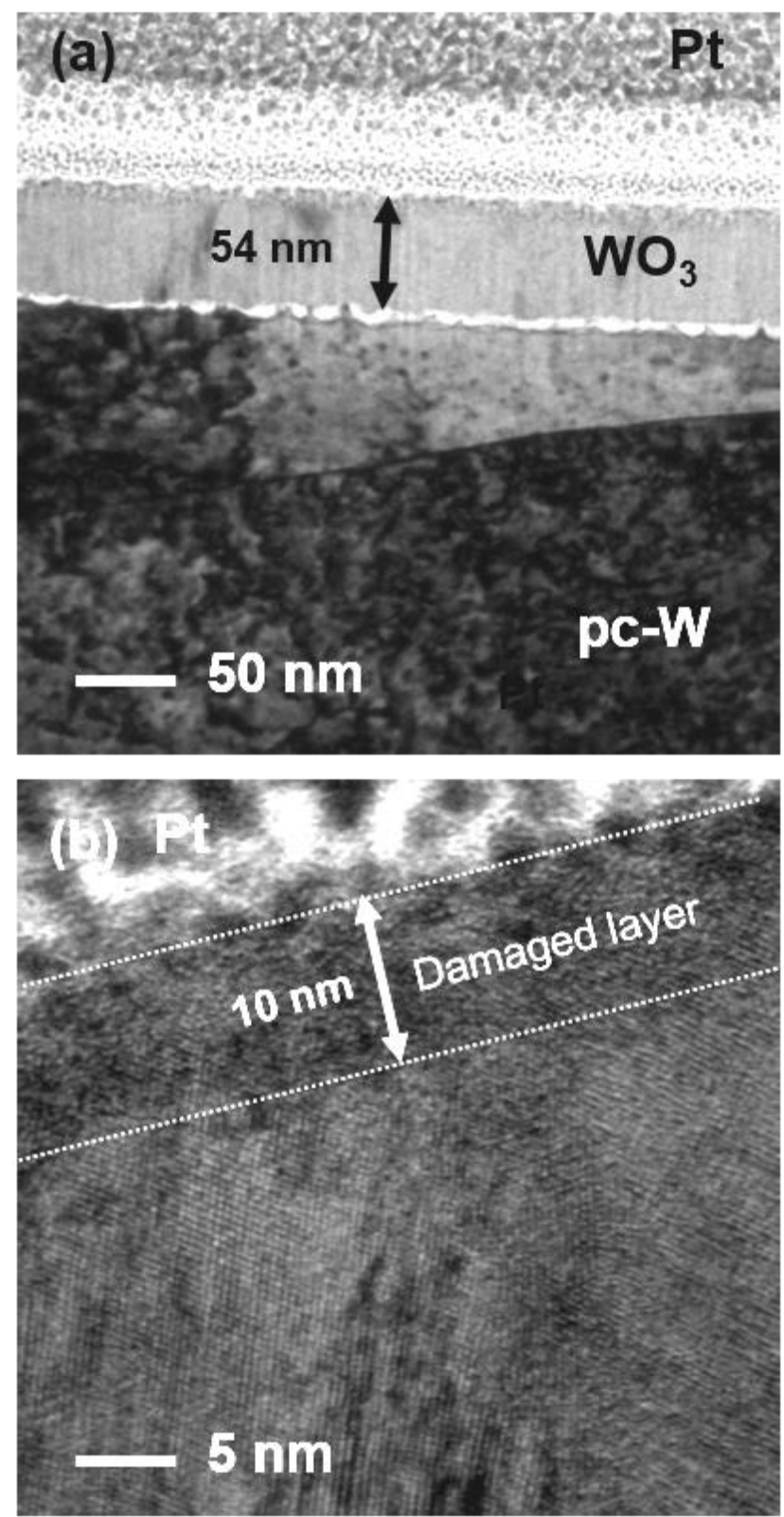
Figure 8

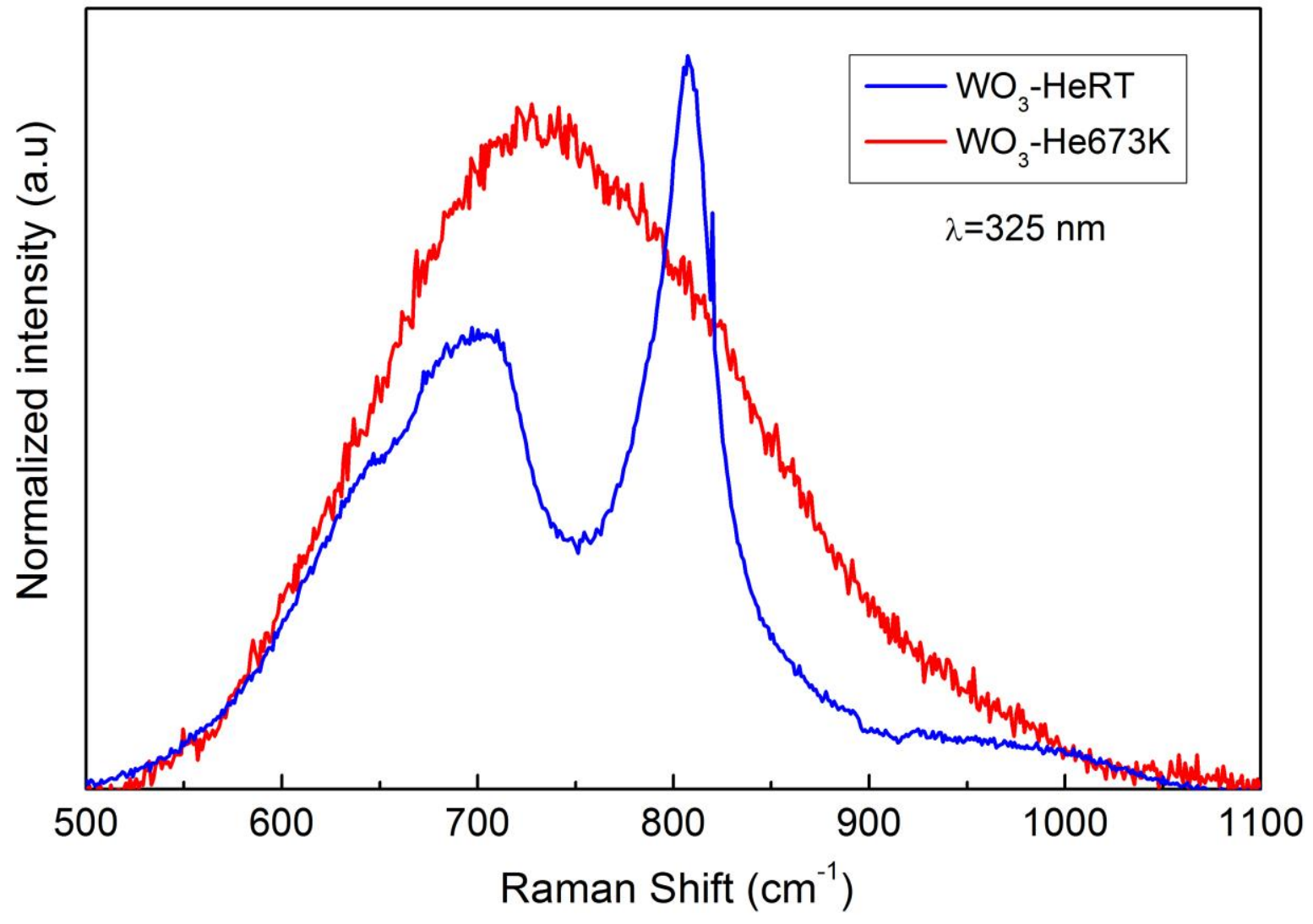


Figure 9

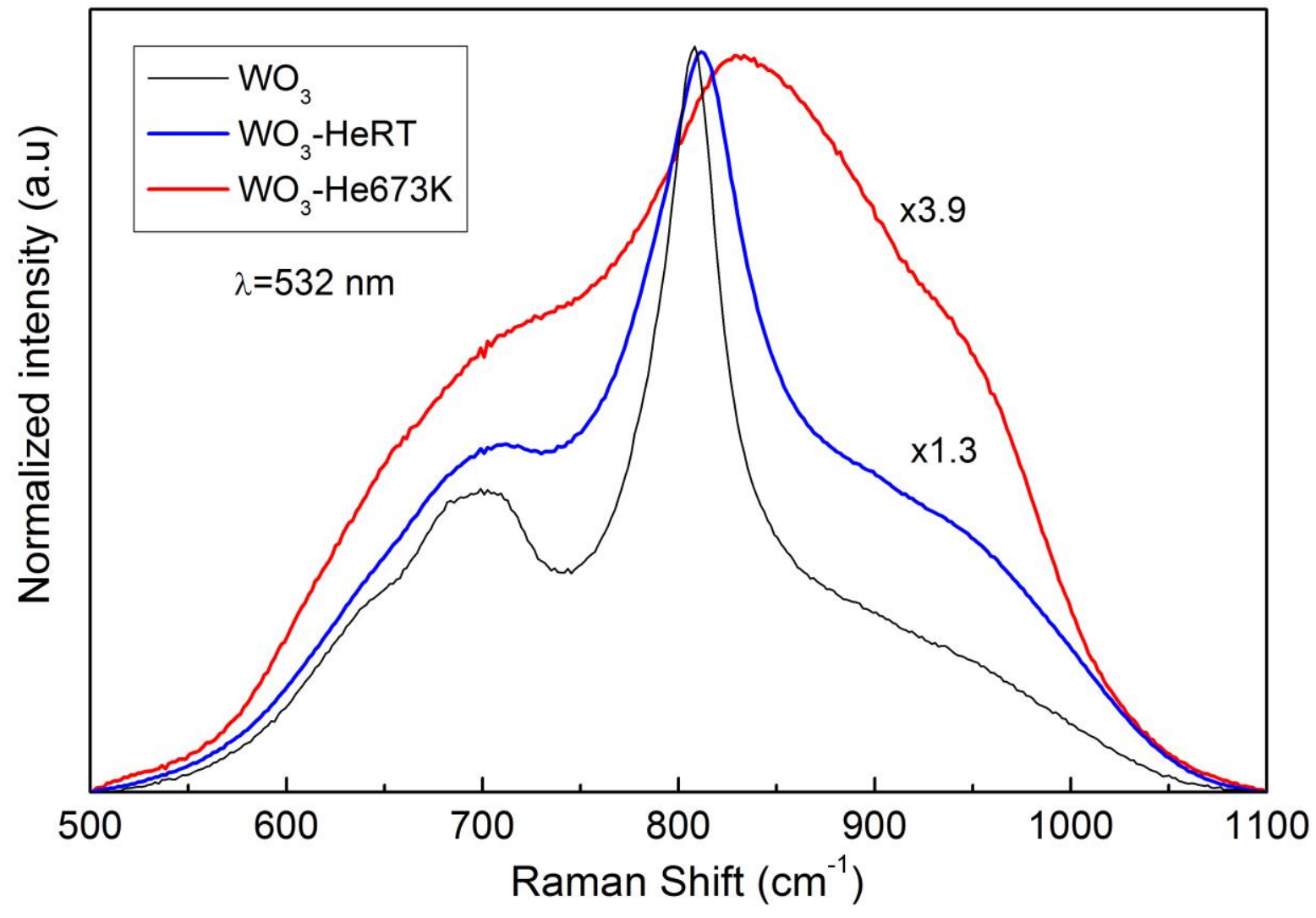

